Proc. Indian Acad. Sci. (Chem. Sci.), Vol. 90, Number 3, June 1981, pp. 215-224.

(C) Printed in India.

\title{
The determination of interfacial tension by differential capillary rise
}

\author{
S RAMAKRISHNAN and S HARTLAND* \\ Swiss Federal Institute of Technology, Department of Industrial and \\ Engineering Chemistry, CH-8092 Zürich, Switzerland
}

MS received 11 January 1977; revised 22 January 1981

\begin{abstract}
A method for directly determining interfacial tension without iteration from the difference in height between two capillaries is presented. An experimental technique is described for organic liquids both lighter and heavier than water, in which the menisci recede over surfaces wetted by the aqueous phase, thus providing the most favourable conditions for zero contact angle. The values determined experimentally using tables prepared from the known shapes of sessile interfaces agree well with accepted values of the interfacial tension.
\end{abstract}

Keywords. Interfacial tension; capillary rise; surface tension.

\section{Intraduction}

Capillary rise is accepted as being one of the most exact methods of measuring surface and interfacial tensions and several workers employed this method to determine the surface tension of liquids (Richards and Coombs 1915; Richards and Carver 1921; Harkins and Brown 1919; Sugden 1921; Richards et al 1924). However it is difficult to locate the flat external meniscus or the free surface of the bulk liquid because of the curvature of the liquid meniscus adhering to the walls. This difficulty may be overcome by using a pair of capillaries and measuring the differential capillary rise. This technique has been used by Mack and Bartell (1932) to measure the interfacial tension of organic liquids against water. In this paper we suggest a refinement of their method which is both simpler and more accurate.

\section{Thearetical}

The shape of the meniscus in the capillary tube is that of a sessile interface, the dimensions of which were determined by Bashforth and Adams (1883) and more recently by Hartland and Hartley (1976). Figure 1a shows a sessile interface in a capillary tube of radius $r$ when the contact angle between the liquid and the

* To whom all correspondence should be made. 


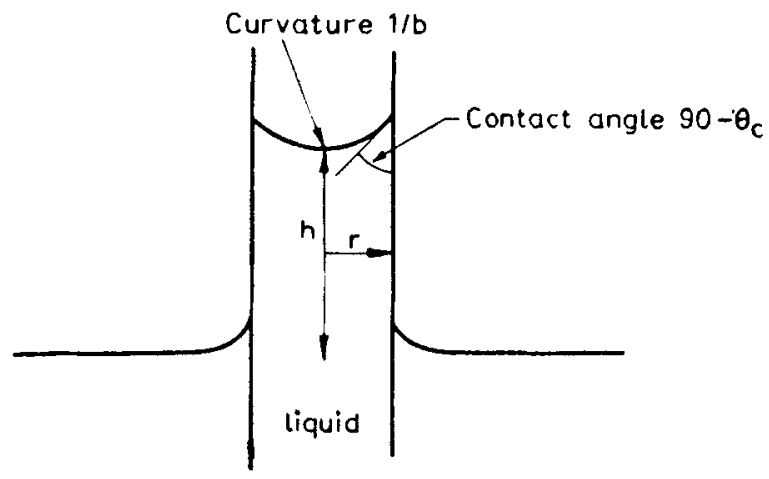

Figure 1a. Notation for capillary rise in a single tube.

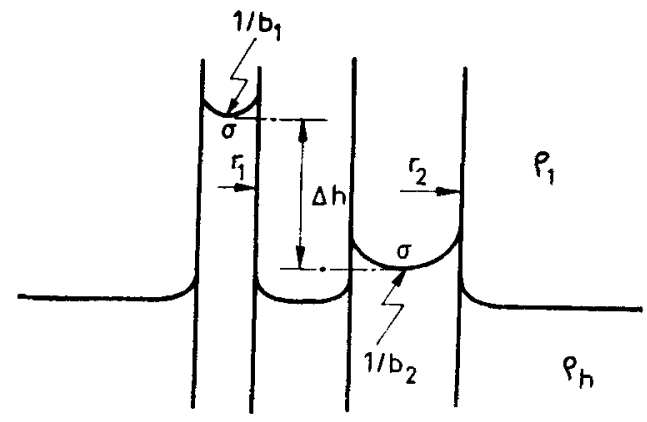

Figure 1b. Notation for differential capillary rise in two tubes of different radii.

wall is $90-\theta_{0}$. The difference in pressure across the apex of the interface is $2 \sigma / b$ and equating this to the gravitational pressure difference of $\Delta \rho g / h$ gives, in dimensionless form

$$
B=2 / H,
$$

where $H=h(\Delta \rho g / \sigma)^{1 / 2}, \quad B=b(\Delta \rho g / \sigma)^{1 / 2}$ and $\Delta \rho=\rho_{h}-\rho_{l}$.

If the contact angle and hence $\theta_{\theta}$ are known, the interfacial tension can be determined. Multiplying both sides of (1) by the radius $r$ of the capillary tube gives

$$
B X_{0}=2 r / h,
$$

since $r(\Delta \rho g / \sigma)^{1 / 2}$ is now equal to $X_{c}$. For a sessile interface $B$ is a unique function of $\theta_{0}$ and $X_{c}$ and so is the product $B X_{c}$. From experimental measurements of $r$ and $h$ we can determine $B X_{0}$ using (2) and hence $X_{0}$ from the tables to define the shape of sessile drops. The interfacial tension can thus be calculated using :

$$
\sigma=\Delta \rho g\left(r / X_{0}\right)^{2} .
$$

If the contact angle is zero, (i.e. $\theta_{0}=90^{\circ}$ ) as is usually assumed, (2) and (3) become

$$
B X_{80}=2 r / h
$$


and $\quad \sigma=\Delta \rho g\left(r / X_{00}\right)^{2}$.

The variation of $X_{90}$ with $\left(B X_{90}\right)^{y^{2}}$ is almost linear for the range of $B$ between 0.12 and 1.6 which covers the experimental values and hence linear interpolation between the tabulated values is almost exact. As the value of $X_{c}$ is not sensitive to $\theta_{c}$ close to $90^{\circ},(4)$ and (5) may be used with confidence when the contact angle is small. For very small tubes, $X_{90} \simeq\left(B X_{90}\right)^{1 / 2}$ and $b \simeq r$, so combining (4) and (5) gives

$$
\sigma=\Delta \rho g \boldsymbol{r} / 2 \text {. }
$$

Equation (1) also reduces directly to this expression when the contact angle is zero. For non-zero contact angles, $b$ is never equal to $r$, no matter how small the tube and the interfacial tension cannot be determined unless the contact angle is known.

As the vessel in which the capillary tube is located is finite the bulk interface is curved and therefore has a small but finite pressure difference across it which is not allowed for in the above equations. In addition it is difficult to exactly locate the position of the interface when viewed from the side. These errors can be avoided by using two tubes of different radii $r_{1}$ and $r_{2}$, as shown in figure $1 \mathrm{~b}$, and measuring the difference in capillary rise $\Delta h$ between them. We may then write

$$
\frac{2 \sigma}{b_{1}}-\frac{2 \sigma}{b_{2}}=\Delta h\left(\rho_{h}-\rho_{l}\right) g
$$

where $b_{1}$ and $b_{2}$ are the radii of curvature at the apex of the two menisci. In dimensionless form the equation becomes

$$
\frac{2}{B_{1}}-\frac{2}{B_{2}}=\Delta H
$$

where $B_{1}=b_{1} c^{1 / 2}, \quad B_{2}=b_{2} c^{1 / 2}, \quad \Delta H=\Delta h c^{1 / 2}$ and $c=\left(\rho_{h}-\rho_{l}\right) g / \sigma$.

From the tables of Hartland and Hartley (1976) the values of $\triangle H$ are calculated from chosen values of $B_{1}$ and $B_{2}$ and values of $R_{1}=r_{1} c^{1 / 2}$ and $R_{2}=r_{2} c^{1 / 2}$ obtained from the corresponding values of $X_{90}$ when the contact angle is zero.

Table 1 presents values of $\log _{10} \Delta H$ corresponding to constant values of $R_{1} / R_{2}$ and $\log _{10} \triangle H / R_{1}$ obtained by interpolation within the original values. The experimental measurements of $\Delta h, r_{1}$ and $r_{2}$ yield the ratios $\Delta h / r_{1}$ and $r_{1} / r_{2}$ which are equal to $\triangle H \mid R_{1}$ and $R_{1} / R_{2}$ respectively. Values of $\triangle H$ may then be obtained from table 1 and the interfacial tension calculated from

$$
\sigma=\left(\rho_{n}-\rho_{l}\right) g(\Delta h / \Delta H)^{2} \text {. }
$$

The variation of $\log _{10} \Delta H$ with $\log _{10} \Delta H / R_{1}$ at constant $R_{1} / R_{2}$ is linear, as shown in figure 2, except for the smallest values of $\log _{10} \triangle H / R_{1}$ and $R_{1} / R_{2}$; so linear interpolation between the values of $\log _{10} \Delta H$ and $\log _{10} \triangle H / R_{1}$ in table 1 is almost exact.

\section{Experimental}

Two quartz capillary tubes of radii 0.3575 and $0.11675 \mathrm{~cm}$ were fused into quartz reservoirs and the arrangement placed in a quartz vessel, as shown in figures $3 a$ 


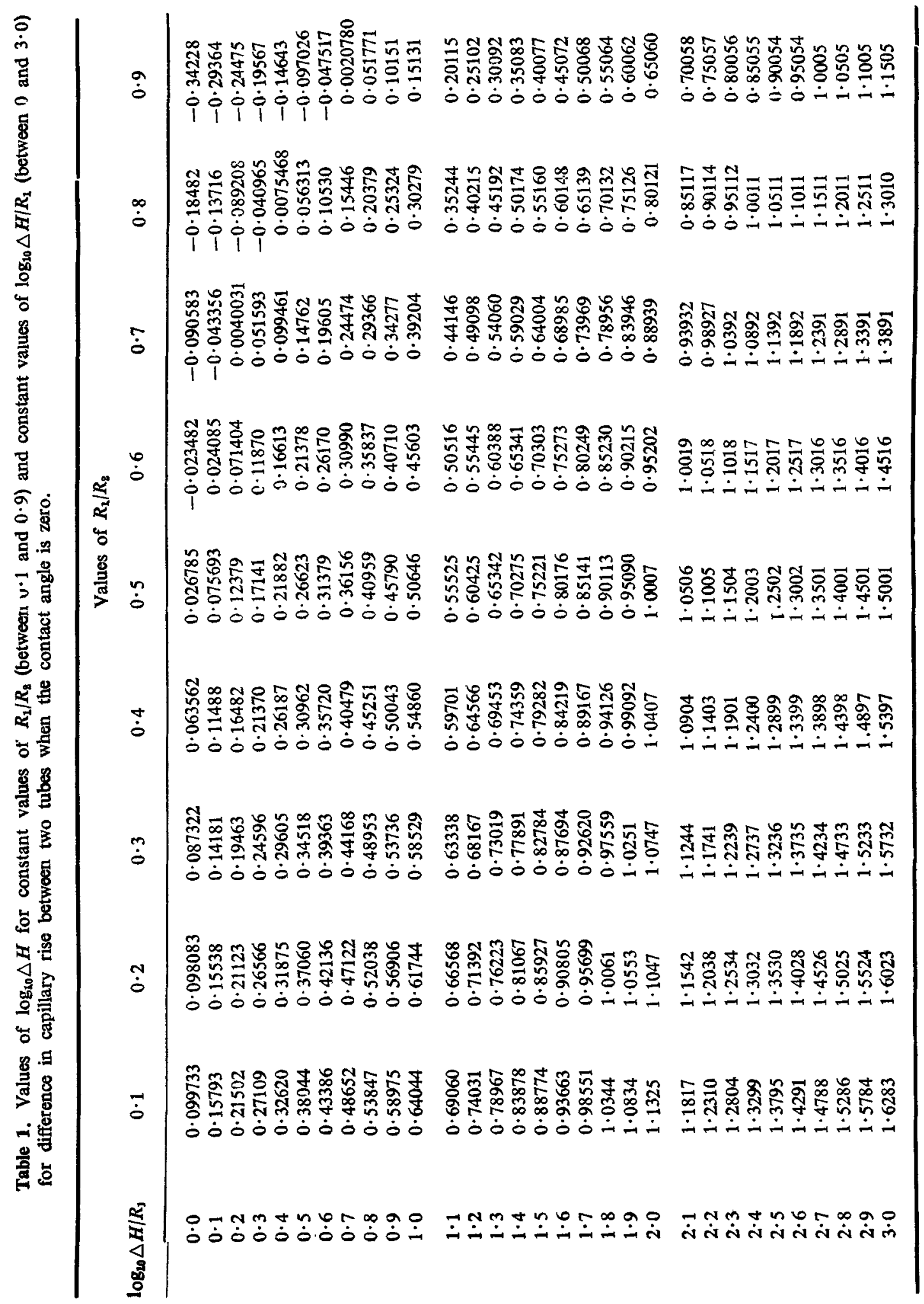




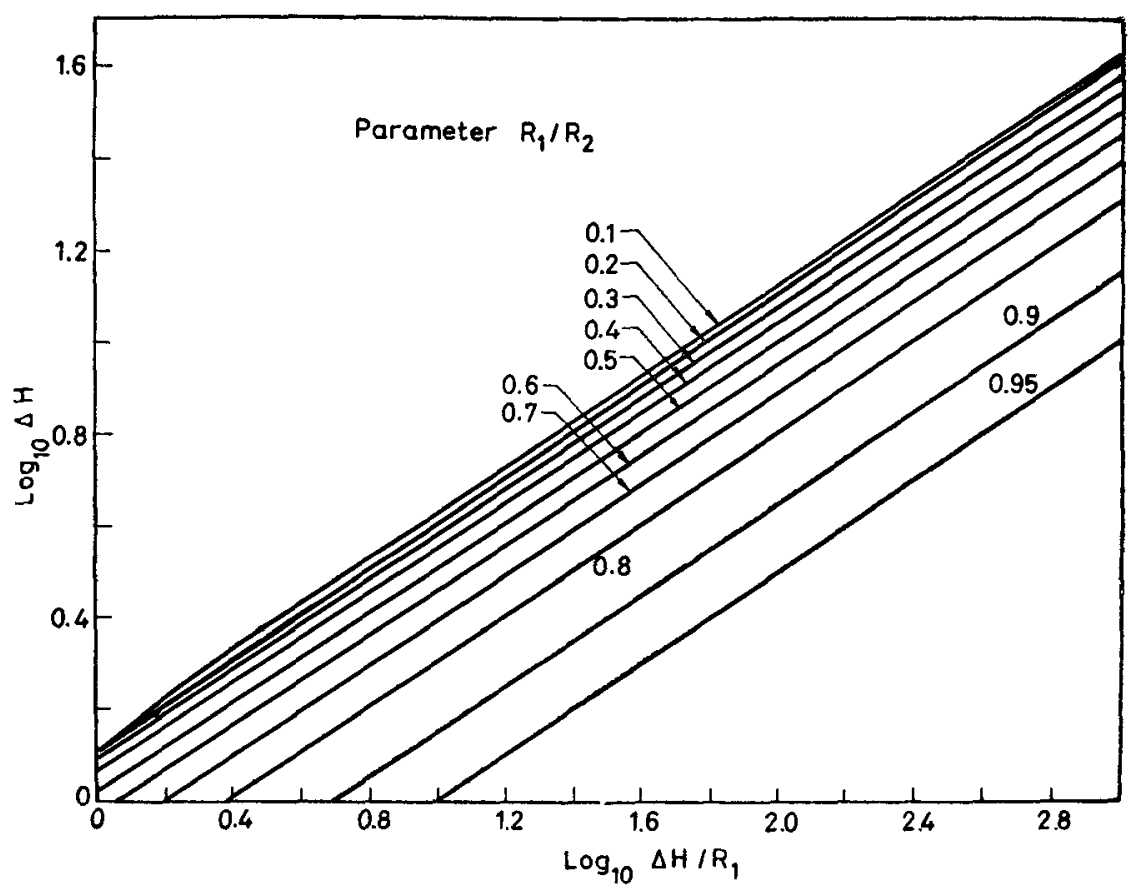

Figure 2. Variation of $\log _{10} \Delta H$ with $\log _{10} \triangle H / R_{1}$ for different values of $R_{1} / R_{2}$ for differential capillary rise.

and $3 \mathrm{~b}$. The capillary tubes could be moved in a vertical direction by vernicr screws. The most important part of the experimental programme is the choice of suitable capillaries. The radius of the capillary should be uniform and must be known exactly. A mercury pellet was accurately weighed and its length at different positions in the capillary was measured to check whether the bore was uniform. The ellipticity of the capillaries was checked by measuring the diameter in four different places with a travelling microscope accurate to $0.01 \mathrm{~mm}$, the capillaries being rejected if any two diameters differed by more than twice the amount.

The capillary tubes and the vessel were initially cleaned with a mixture of nitric acid and ethanol, rinsed with hot detergent solution and then several times with doubled-distilled water (Wilkinson et al 1979). The capillaries were not dried as they had to be initially wetted by water. The organic liquids were of Fluka Puriss grade; water was distilled in a quartz still. The differential capillary height was measured using a cathetometer (accurate to $0.01 \mathrm{~mm}$ ) which was also used to check the verticality of the capillary tubes in two mutually perpendicular directions. The equipment was surrounded by a water bath controlled to $0 \cdot 1^{\circ} \mathrm{C}$. The experimental procedure adopted depended on whether the organic liquid was lighter or heavier than water.

\subsection{Organic liquid lighter than water}

Water was slowly poured into the vessel till the menisci rose through the capillaries, finally filling a small portion of the reservoir to which the capillary tubes 

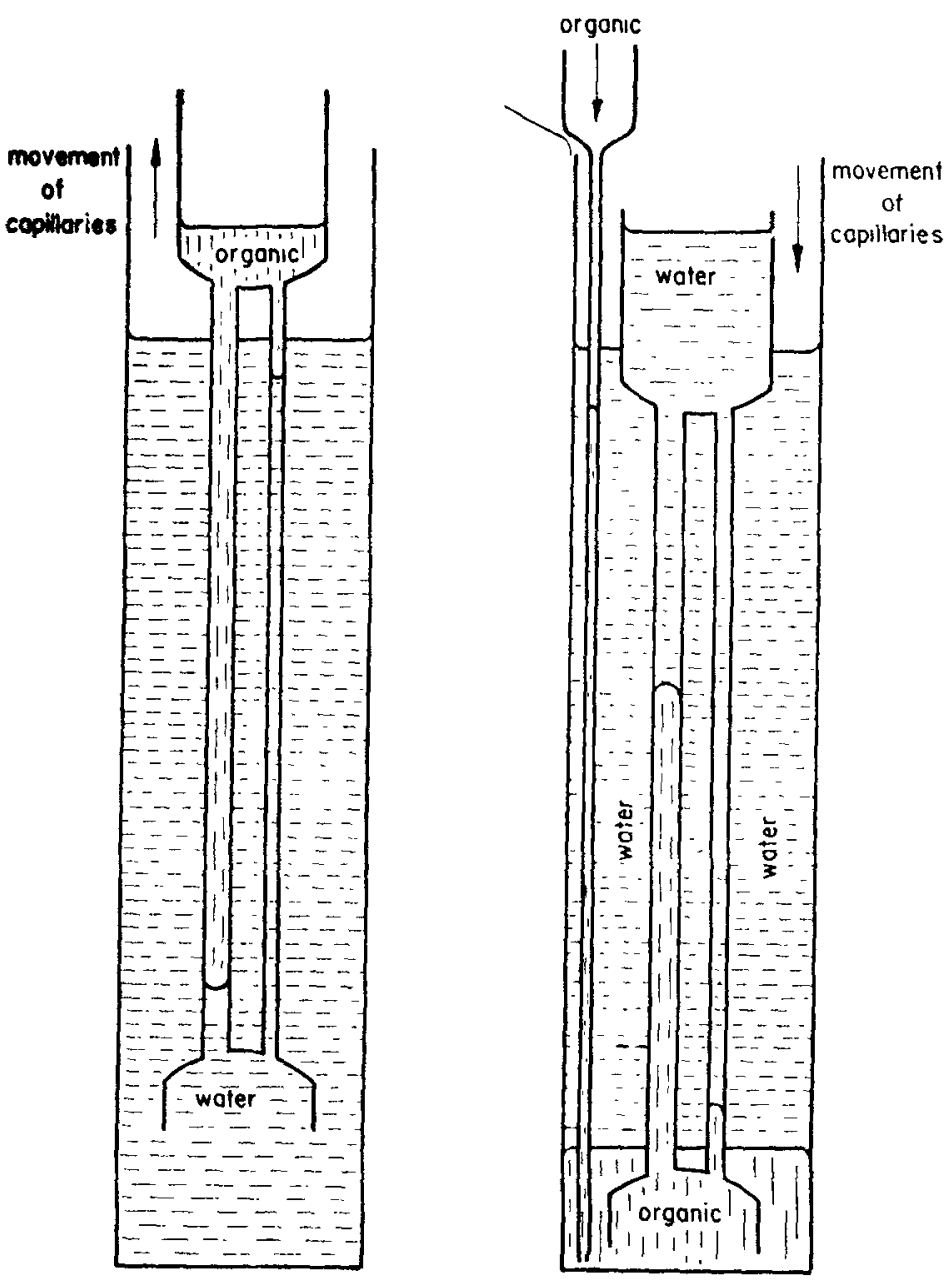

Figure 3. Measurement of interfacial tension using differential capillary rise : (a) organic phase lighter than water. (b) organic phase heavier than water.

were fused, as shown in figure $3 a$. This ensured that the capillaries were wet by water before the organic liquid was admitted (Richards and Carver 1921). Reynolds (1921) emphasized that the perfectly cleaned tube must be completely filled with the liquid having the greater surface tension (in general, an aqueous solution) and the other immiscible liquid must travel continuously in one direction only. A small quantity of the lighter organic liquid was then added to the upper reservoir, the interface still remaining inside this reservoir. The reservoirs and capillary tubes were then moved slowly and continuously upwards so the interface moved down, finally forming two menisci in the two capillaries. The differential height was measured. Measurements were repeated at regular time intervals until the steady state was reached (usually after about $30 \mathrm{~min}$.).

\subsection{Organic liquid heavier than water}

The capillary tubes, reservoirs and vessel were filled with water as before. The organic liquid was then introduced slowly near the bottom of the vessel through 
a tube inserted between the reservoir and the vessel wall, as shown in figure $3 \mathrm{~b}$. The liquid collected at the base of the vessel until an interface was formed in the lower reservoir. The capillary tubes and reservoirs were then moved slowly downwards so the menisci rose into the capillaries. (The menisci formed in the capillaries were curved upwards, as water wets glass better than the organic liquid used). The differential height was measured. Measurements were repeated at regular time intervals until the steady state was reached.

\section{Results}

The values of interfacial tension for the different liquids used are given in table 2 . The values are quoted at $20^{\circ} \mathrm{C}$ and represent the average of at least five measurements. The densities of the liquids are taken from the Handbook of Chemistry and Physics (1973-74). The literature values of interfacial tension are taken from the International Critical Tables (1928), except for heptane which is taken from Krynitsky and Garrett (1963). Table 3 gives values of interfacial tension published by different authors. The method may also be used without difficulty for measuring surface tensions, providing the liquid used wets the quartz capillaries, which is the usual case in practice. (Contact angles between 0 and $10^{\circ}$ have very little effect on the predicted values). We have measured the surface tension of 16 organic liquids (including water). Five pairs of capillaries with values of $R_{1} / R_{2}$ equal to $0.8445,0.5014,0.4275,0.3495$ and 0.3062 were used. These measurements showed that the accuracy increased as the ratio $R_{1} / R_{2}$ decreased, being better than $0.1 \mathrm{dyn} / \mathrm{cm}$ for the smallest ratio. We therefore chose a ratio of 0.3062 for the measurement of interfacial tension.

\subsection{Errors}

Differentiating (9) shows that the fractional error in $\sigma$ is given by

$$
\frac{d \sigma}{\sigma}=\frac{d \Delta \rho}{\triangle \rho}+\frac{d g}{g}+\frac{2 d \triangle h}{\Delta h}-\frac{2 d \triangle H}{\triangle H} .
$$

Since $\Delta H$ is a function of $R_{1} / R_{2}\left(=r_{1} / r_{2}\right)$ and $\Delta H / R_{1}\left(=\Delta h / r_{1}\right)$ we may write

$$
\frac{d \triangle H}{\triangle H}=M_{1} \frac{d\left(r_{1} / r_{2}\right)}{r_{1} / r_{2}}+M_{2} \frac{d\left(\triangle h / r_{1}\right)}{\triangle h / r_{1}}
$$

Table 2. Experimental values of interfacial tensions of organic liquids against

\begin{tabular}{|c|c|c|c|c|c|}
\hline System & $\begin{array}{r}\Delta \rho \\
\mathrm{g} / \mathrm{cm}^{3}\end{array}$ & $\underset{\mathrm{cm}}{\Delta h}$ & $\log _{10} \Delta h / r_{1}$ & $\begin{array}{c}\sigma_{\text {exp }} \\
\mathrm{dyn} / \mathrm{cm}\end{array}$ & $\begin{array}{r}\sigma_{1 \mathrm{it}}^{(17)} \\
\mathrm{dyn} / \mathrm{cm}\end{array}$ \\
\hline Benzene & $0 \cdot 1195$ & $11 \cdot 596$ & $2 \cdot 5110$ & $34 \cdot 94$ & $35.00 \pm 0.05$ \\
\hline Tert. butylchloride & $0 \cdot 1562$ & 6.011 & $2 \cdot 2257$ & $23 \cdot 62$ & $23 \cdot 75$ \\
\hline Carbon tetrachloride & 0.5958 & $3 \cdot 033$ & $1 \cdot 9286$ & $45 \cdot 27$ & $45 \cdot 00 \pm 1 \cdot 0$ \\
\hline Diethylether & $0 \cdot 2844$ & $1 \cdot 518$ & $1 \cdot 6280$ & $10 \cdot 73$ & $10 \cdot 70 \pm 0.2$ \\
\hline Heptane & 0.3152 & 6.447 & $2 \cdot 2561$ & $51 \cdot 14$ & $50 \cdot 40-51 \cdot 4^{(22)}$ \\
\hline
\end{tabular}
water using pair of capillaries, with $r_{1} / r_{8}=0 \cdot 30621$. 
Table 3. Interfacial tension of various liquids in dyn $/ \mathrm{cm}$ against water at $20^{\circ} \mathrm{C}$ (some values are given at $25^{\circ} \mathrm{C}$ as indicated)

\begin{tabular}{|c|c|c|c|c|c|c|}
\hline Author & Method E & Benzene & $\begin{array}{l}\text { Tert. } \\
\text { butyl- } \\
\text { chloride }\end{array}$ & $\begin{array}{c}\text { Carbon } \\
\text { tetra- } \\
\text { chloride }\end{array}$ & $\begin{array}{l}\text { Diethyl- } \\
\text { ether }\end{array}$ & Heptane \\
\hline Landolt--Börnstein (1905) & Reported value & $33 \cdot 6$ & & & & \\
\hline Harkins and Humphery (1916) & Capillary rise & $34 \cdot 52$ & & & & \\
\hline Harkins et al (1920) & Drop weight & $35 \cdot 03$ & $23 \cdot 75$ & $43 \cdot 26$ & & \\
\hline Harkins and Cheing (1921) & Drop weight & $34 \cdot 96$ & & $45 \cdot 05$ & & \\
\hline Reynolds (1921) & Capillary rise & $34 \cdot 4$ & & $43 \cdot 8$ & & \\
\hline Bartell and Miller (1928) & Capillary rise & $\begin{array}{l}34.85 \\
34.94\end{array}$ & & & $\begin{array}{l}10 \cdot 62 \\
\left(25^{\circ} \mathrm{C}\right) \\
10 \cdot 74 \\
\left(25^{\circ} \mathrm{C}\right)\end{array}$ & \\
\hline Harkins (1928) & Drop weight & $35 \cdot 03$ & $23 \cdot 75$ & $43 \cdot 26$ & & \\
\hline Int. Critical Tables (1928) & Reported value & $\begin{array}{c}35 \cdot 0 \pm \\
0 \cdot 05\end{array}$ & $23 \cdot 75$ & $\begin{array}{c}45 \cdot 0 \pm 1 \\
1 \cdot 0\end{array}$ & $\begin{array}{l}10 \cdot 70 \pm \\
0 \cdot 2\end{array}$ & \\
\hline Mack and Bartell (1932) & Double Capillary & $\begin{array}{r}35 \cdot 00 \\
35.03 \\
34.97\end{array}$ & & $43 \cdot 94$ & & \\
\hline Bartell et al (1933) & Capillary rise & $34 \cdot 21$ & & $43 \cdot 99$ & & \\
\hline Andreas et al (1938) & Pendent drop & $30 \cdot 39$ & & $44 \cdot 34$ & $\begin{array}{l}11 \cdot 05 \\
\left(25^{\circ} \mathrm{C}\right)\end{array}$ & \\
\hline Donahue and Bartell (1952) & Pendent drop & $34 \cdot 39$ & & $44 \cdot 19$ & $\begin{array}{l}11 \cdot 00 \\
\left(25^{\circ} \mathrm{C}\right)\end{array}$ & \\
\hline $\begin{array}{l}\text { Girifalco and Good (1957) } \\
\text { Krynitsky and Garrett (1963) }\end{array}$ & $\begin{array}{l}\text { Calculated } \\
\text { Ring }\end{array}$ & $35 \cdot 0$ & $23 \cdot 75$ & $45 \cdot 0$ & $10 \cdot 7$ & $\begin{array}{l}50 \cdot 2 \\
50 \cdot 4 \\
50 \cdot 4 \\
51 \cdot 4\end{array}$ \\
\hline $\begin{array}{l}\text { Harkins and Alexander (1965) } \\
\text { Padday and Uffindell (1968) }\end{array}$ & $\begin{array}{l}\text { Reported value } \\
\text { Calculated }\end{array}$ & $34 \cdot 96$ & & $45 \cdot 05$ & & $\begin{array}{l}52 \cdot 55 \\
53 \cdot 6\end{array}$ \\
\hline $\begin{array}{l}\text { Handbook of Chem. Phys. } \\
(1973-74)\end{array}$ & $\begin{array}{l}\text { Reported } \\
\text { value }\end{array}$ & 35.00 & & $45 \cdot 00$ & $10 \cdot 7$ & \\
\hline Tornberg (1977) & Pendent drop & $\begin{array}{c}33 \cdot 35 \pm \\
0 \cdot 06\end{array}$ & & & $\begin{array}{c}10 \cdot 81 \pm \\
0 \cdot 10\end{array}$ & \\
\hline Aronson and Princen (1978) & Rotating drop & $\begin{array}{c}35 \cdot 4 \pm \\
1 \cdot 0\end{array}$ & & & & \\
\hline Present work & Double capillary & y 34.94 & $23 \cdot 62$ & $45 \cdot 27$ & $10 \cdot 73$ & $51 \cdot 14$ \\
\hline
\end{tabular}

where $\quad M_{1}=\left.\frac{R_{1} / R_{2}}{\Delta H}\left(\frac{\partial \Delta H}{\partial\left(R_{1} / R_{2}\right)}\right)\right|_{\Delta H / R_{1}}$

and $\quad M_{2}=\left.\frac{\Delta H / R_{1}}{\Delta H}\left(\frac{\partial \Delta H}{\partial\left(\Delta H / R_{1}\right)}\right)\right|_{B_{1} / R_{2}}$

Expanding $d\left(r_{1} / r_{2}\right)$ and $d\left(\Delta h / r_{1}\right)$, assuming the fractional errors in $r_{1}$ and $r_{2}$ are both equal to $d r / r$ and taking proper regard of the sign of $d \Delta h / \Delta h$ in (10) and (11) shows that the maximum fractional error in $\sigma$ may be estimated by

$$
\begin{aligned}
\frac{|d \sigma|}{\sigma} & =\frac{|d \Delta \rho|}{\Delta \rho}+\frac{|d g|}{g}+2\left(1-M_{2}\right) \frac{|d \Delta h|}{\Delta h} \\
& +2\left(2 M_{1}+M_{2}\right) \frac{|d r|}{r} .
\end{aligned}
$$


The fractional error in $g\left(=9.80686 \mathrm{~m} / \mathrm{s}^{2}\right.$ at the ETH Zürich $)$ may be neglected. Densities are known to the fourth decimal place so the error in $\Delta \rho$ is less than 0.002 for interfacial tensions. The density differences lie between $0 \cdot 1195 \cdot 10^{3}$ and $0 \cdot 5958 \cdot 10^{3} \mathrm{~kg} / \mathrm{m}^{3}$, so the fractional error is from 0.0017 to 0.00034 . The height difference $\Delta h$ can be measured to $0.01 \mathrm{~mm}$ and the values of $\triangle h$ are between 15.18 and $115.96 \mathrm{~mm}$ so the values of $d \triangle h / \triangle h$ lie between 0.00066 and 0.00009 . The radius of each capillary was found by weighing a mercury pellet and measuring its length $l$ at different positions with a travelling microscope, the resulting fractional error in $r$ being less than 0.0012 .

Values of $M_{1}$ were found by varying the value of $R_{1} / R_{2}$ about the experimental value of 0.3062 at the constant values of $\log _{10} \triangle H / R_{1} 1 \cdot 6,2 \cdot 1$ and $2 \cdot 6$ (which cover the experimental range) and determining the change in $\triangle H$. Values of $M_{2}$ were similarly found by varying the value of $\triangle H / R_{1}$ about the three values of $1 \cdot 6,2 \cdot 1$ and $2 \cdot 6$ of $\log _{10} \Delta H / R_{1}$ for the constant value of $R_{1} / R_{2}$ of $0 \cdot 3062$. The values of $M_{1}$ varied between 0.233 and 0.222 and hence were almost independent of $\triangle H / R_{1}$. The values of $M_{2}$ changed from 0.489 to 0.496 being practically independent of $\triangle H ! R_{1}$.

The fractional error in $\sigma$ was found by adding together the fractional errors in $r, \Delta \rho$ and $\Delta h$, as indicated in (12). The values of $d \sigma / \sigma$ lie between 0.0031 and 0.0027 , corresponding to an absolute error in $\sigma$ of about $0.1 \mathrm{dyn} / \mathrm{cm}$. Note that these limiting values do not usually occur at the maximum and minimum values of $d \Delta \rho / \Delta \rho$ or $d \Delta h / \Delta h$ has the fractional error in $\sigma$ is dominated by that in $r$ because of the large multiplying factor $2\left(2 M_{1}+M_{2}\right)$.

\section{Acknowledgements}

Some tabulated values were calculated by $\mathbf{R}$ W Hartley, and some experimental values determined by $\mathbf{J}$ Miszak.

\section{List af symbals}

$b$ radius of curvature at apex of sessile interface

$B=b c^{1 / 2} \quad$ dimensionless $b$

$c=\Delta \rho g / \sigma \quad$ constant characterizing physical properties

$g$ acceleration due to gravity

$h \quad$ capillary rise

$\triangle h \quad$ differential capillary rise

$H=h c^{1 / 2} \quad$ dimensionless $h$

$\Delta H=\Delta h c^{1 / 2}$ dimensionless $\Delta h$

$M_{1}, M_{2} \quad$ constants

$r \quad$ radius of tube

$R=r c^{1 / 2} \quad$ dimensionless $r$

$x$ radial distance from axis of symmetry of sessile interface 


$\begin{array}{ll}X=x c^{1 / 2} & \text { dimensionless } x \\ \theta & \text { angle of inclination of sessile interface to horizontal } \\ \rho & \text { density } \\ \Delta \rho & \text { density difference } \\ \sigma & \text { interfacial tension }\end{array}$

\section{Subscripts}

value referring to first interface or tube value referring to second interface or tube

$c$ value where $\theta=90^{\circ}$ contact circle heavy liquid

light liquid

\section{References}

Andreas J M, Hauser E A and Tucker W B 1938 J. Phys. Chem. 421001

Aronson M P and Princen H M $1978 \mathrm{~J}$. Chem. Soc. Faraday Trans. I 74555

Bartell F E, Case L O and Brown H 1933 J. Am. Chem. Soc. 552769

Bartell F E and Miller F L 1928 J. Am. Chem. Soc. 501961

Bashforth F and Adams J C 1883 An attempt to test the theories of capillary action (Cambridge : University Press)

Donahue D U and Bartell F E 1952 J. Phys. Chem. 56480

Girifalco L A and Good R J 1957 J. Phys. Chem. 61904

Handbook of chemistry and physics 1973-74 (Ohio : CRC Press) 54th ed. p. F-39

Harksins W D 1928 Coll. Symp. Monogr. (New York: Chem. Catalog Co.) (ed. H B Weiser) p. 17

Harkins W D and Alexander A E 1965 Physical methods of organic chemistry (ed. A Weissberger) ed. III, Vol. 1, p. 757

Harkins W D and Brown F E 1919 J. Am. Chem. Soc. 43827

Harkins W D and Cheng Y C $1921 \mathrm{~J}$. Am. Chem. Soc. 4335

Harkins W D, Clark G L and Roberts L E $1920 \mathrm{~J}$. Am. Chem. Soc. 42700

Harkins W D and Humphrey E C 1916 J. Am. Chem. Soc. 38242

Hartland S and Hartley J W 1976 Axisymmetric fluidlliquid interfaces (Amsterdam : Elsevier) International Critical Tables 1928 (New York: McGraw Hill) Vol. 4

Krynitsky J A and Garrett W D 1963 J. Coll. Sci. 18893

Landolt-Bcrnstein 1905 Physikalische Chemische Tabellen Verlag von Julius (Berlin: Springer) p. 113

Mack G L and Bartell F E 1932 J. Am. Chem. Soc. 54936

Padday J F and Uffindell N D 1968 J. Phys. Chem. 721407

Reynolds W C 1921 J. Chem. Soc. 119460

Richards T W and Carver E K $1921 \mathrm{~J}$. Am. Chem. Soc. 43827

Richards T W and Coombs L B $1915 \mathrm{~J}$. Am. Chem. Soc. 371656

Richards T W, Speyers C L and Carver E K 1924 J. Am. Chem. Soc. 461196

Sugden S $1921 \mathrm{~J}$. Chem. Soc. Trans. 1191483

Tornberg E 1977 J. Colloid Interface Sci. 6050

Wilkinson M C, Ellis R, Aronson M P, van der Hoff J W and Zettlemoyer A C 1979 J. Colloid. Inteface Sci. 68545 